\title{
Conflict of interest policies and disclosure requirements among European Society of Cardiology national cardiovascular journals
}

\author{
F. Alfonso • A. Timmis • F. J. Pinto • G. Ambrosio • \\ H. Ector • P. Kulakowski • P. Vardas • \\ on behalf of the Editors' Network European Society \\ of Cardiology Task Force
}

Published online: 1 June 2012

(C) Springer Media / Bohn Stafleu van Loghum 2012
COI-related issues. New insights into current COI policies and practices among European Society of Cardiology national cardiovascular journals, as derived from a cross-sectional survey using a standardised questionnaire, are discussed.

Keywords Conflict of interest - Disclosure - Editorial ethics . Journals
This is a joint simultaneous publication initiative involving all interested National and Affiliated Cardiovascular Journals of the European Society of Cardiology

Loizos Antoniades 1 , Mansoor Ahmad 2 , Eduard Apetrei ${ }_{3}$, Kaduo Arai ${ }_{4}$, Jean-Yves Artigou 5 , Michael Aschermann 6 , Michael Bohm 7 , Leonardo Bolognese $_{8}$, Raffaele Bugiardini ${ }_{9}$, Ariel Cohen ${ }_{10}$, Istvan Edes ${ }_{11}$, Joseph Elias 12 , Javier Galeano ${ }_{13}$, Eduardo Guarda 14 , Habib Haouala ${ }_{15}$, Magda Heras $_{16}$, Christer Höglund 17 , Kurt Huber 18 , Ivan Hulin 19 , Mario Ivanusa $_{20}$, Rungroj Krittayaphong 21 , Chi-Tai $\mathrm{Kuo}_{22}$, Chu-Pak $\mathrm{Lau}_{23}$, Victor A Lyusov 24 , Germanas Marinskis 25 , Manlio F Marquez $_{26}$, Izet Masic 27 , Luiz Felipe Pinho Moreira 28 , Alexander Mrochek $_{29}$, Rafael G Oganov 30,31 , Dimitar Raev 32 , Mamanti Rogava $_{33}$, Olaf Rødevand 34 , Vedat Sansoy ${ }_{35}$, Hiroaki Shimokawa ${ }_{36}$, Valentin A Shumakov ${ }_{37}$, Carlos Daniel Tajer ${ }_{38}$, Ernst E van der Wall ${ }_{39}$, Christodoulos Stefanadis 40 , Jørgen Videbæk ${ }_{41}$, Thomas F Lüscher 42 . ${ }_{1}$ Editor-in-Chief, Cyprus Heart Journal; ${ }_{2}$ Editor-in-Chief, Pakistan Heart Journal; ${ }_{3}$ Editor-in-Chief, Romanian Journal of Cardiology; ${ }_{4}$ Editor-in-Chief, Avances Cardiologicos; ${ }_{5}$ Editor-in-Chief, Archives des maladies du coeur et des vaisseaux Pratique; ${ }_{6}$ Editor-in-Chief, Cor et Vasa; ${ }_{7}$ Editor-in-Chief, Clinical Research in Cardiology; ${ }_{8}$ Editor-inChief, Giornale Italiano Di Cardiologia; ${ }_{9}$ Editor-in-Chief, Journal of Cardiovascular Medicine; ${ }_{10}$ Editor-in-Chief, Archives of Cardiovascular Diseases; ${ }_{11}$ Editor-in-Chief,Cardiologia Hungarica; ${ }_{12}$ Editor-in-Chief, Heart News; ${ }_{13}$ Editor-in-Chief, Journal of the Paraguayan Society of Cardiology; ${ }_{14}$ Editor-in-Chief, Revista Chilena de Cardiologia; ${ }_{15}$ Editor-in-Chief, Cardiologie Tunisienne; ${ }_{16}$ Editor-inChief, Revista Espaòola de Cardiologia; ${ }_{17}$ Editor-in-Chief, Svensk Cardiologi; ${ }_{18}$ Editor-in-Chief, Journal für Kardiologie; ${ }_{19}$ Editor-inChief, Cardiology Letters/Kardiologia; ${ }_{20}$ Editor-in-Chief, Kardio List; ${ }_{21}$ Editor-in-Chief, Thai Heart Journal; ${ }_{22}$ Editor-in-Chief, Acta Cardiologica Sinica; ${ }_{23}$ Editor-in-Chief, Journal of the Hong Kong
College of Cardiology; ${ }_{24}$ Editor-in-Chief, Russian Cardiology Journal; ${ }_{25}$ Editor-in-Chief, Seminars in Cardiovascular Medicine; ${ }_{26}$ Editor-inChief, Archivos de Cardiologia de Mexico; ${ }_{27}$ Editor-in-Chief, Medical Archives; ${ }_{28}$ Editor-in-Chief, Arquivos Brasileiros de Cardiologia; ${ }_{29}$ Editor-in-Chief, Cardiology in Belarus; ${ }_{30}$ Editor-in-Chief, Cardiovascular Therapy and Prevention; ${ }_{31}$ Editor-in-Chief, Rational Pharmacotherapy in Cardiology; ${ }_{32}$ Editor-in-Chief, Bulgarian Cardiology; ${ }_{33}$ Editor-in-Chief, Cardiology and Internal Medicine XXI; ${ }_{34}$ Editor-in-Chief, Hjerteforum; ${ }_{35}$ Editor-in-Chief, Archives of the Turkish Society of Cardiology; ${ }_{36}$ Editor-in-Chief, Circulation Journal; ${ }_{37}$ Editor-in-Chief, Ukrainian Journal of Cardiology; ${ }_{38}$ Editor-in-Chief, Revista Argentina de Cardiologia; ${ }_{3}$ Editor-in-Chief, Netherlands Heart Journal; ${ }_{40}$ Editors-in-Chief, Hellenic Journal of Cardiology; ${ }_{41}$ Editor-in-Chief, Cardiologisk Forum; ${ }_{42}$ Editor-in-Chief, Kardiovaskuläre Medizin.

\section{F. Alfonso $(\bowtie)$ \\ Clinico San Carlos, \\ Madrid, Spain \\ e-mail: falf@hotmail.com}

\section{A. Timmis}

Department of Cardiology, London Chest Hospital, London, UK

\section{F. J. Pinto}

Department of Cardiology, Lisbon University Medical School, Lisbon, Portugal 


\section{Introduction}

The scientific process relies on trust and credibility [1-5]. The scientific community demands high ethical standards in biomedical research and the publication of scientific content [1-5]. During the past decade, disclosure of conflicts of interest (COI) (also called competing loyalties, competing interests or dual commitments) has been considered as key to guaranteeing the credibility of the scientific process [6-10]. Biases in design, analysis and interpretation of studies may arise when authors or sponsors have vested interests [6-10]. Therefore, COI should be made clear to the readers to facilitate their own judgement and interpretation of their relevance and potential implications. Authors are responsible for fully disclosing potential COI [6-10]. Failure to do so has shaken the confidence of the public, health professionals and scientists in the peerreviewed medical literature [6-10].

According to the International Committee of Medical Journal Editors (ICMJE) COI exist when an author (or the author's institution), reviewer or editor has financial or personal relationships that inappropriately influence (bias) his or her actions $[1,11,12]$. The potential for COI exists regardless of whether the individual believes that the relationships affect his or her scientific judgement. Aside from financial relationships, COI may emerge from personal relationships, academic competition and intellectual passion. To prevent ambiguity, authors should be explicitly asked to state whether COI exist or do not exist. Editors should publish this information if they believe it is important in judging the manuscript $[1,11,12]$.

Traditionally, biomedical journals have followed standard practices to ensure COI disclosure. Further efforts to improve transparency and protect the integrity of research, including specific recommendations and guidelines to disclose COI, have been recently proposed by many organisations [1-10]. However, ensuring adequate reporting of all sources of financial support is becoming increasingly challenging for editors as a result of the growing complexity of funding mechanisms. Furthermore, journals have

\author{
G. Ambrosio \\ University of Perugia School of Medicine, \\ Perugia, Italy \\ H. Ector \\ Acta Cardiologica, \\ Weldadigheidsstraat 49, \\ 3000, Leuven, Belgium \\ P. Kulakowski \\ Kardiologia Polska, \\ Warsaw, Poland \\ P. Vardas \\ Cardiology Department, Heraklion University Hospital, \\ Heraklion, Greece
}

different policies about COI disclosure which can cause confusion as the same author may report different information in different journals which, in turn, might jeopardise the confidence of the readers $[11,12]$. To overcome these problems, the ICMJE proposed the use of a common vehicle to report COI and, in October 2009, launched an electronic 'uniform' format for COI disclosure [11, 12].

The Editors' Network of the European Society of Cardiology (ESC) is committed to promoting the dissemination and implementation of high-quality editorial standards among ESC National Societies Cardiovascular Journals (NSCJ) [13-16]. This report examines the issue of COI from a global and didactic perspective and provides new insights into current policies and practices among ESC NSCJ.

\section{Conflict of interest questionnaire and survey}

To determine the status of COI and disclosure requirements among ESC NSCJ a web-based, comprehensive, structured and standardised questionnaire was specifically devised. The questionnaire was exhaustive and dealt with all relevant editorial topics related to COI. Previous publications on COI (from year 2005 to 2010) were retrieved from PubMed (Medline search terms: 'conflict of interest', 'competing interest' and 'disclosure') and carefully reviewed to identify issues relevant to COI. Items included in the questionnaire were eventually determined after an internal discussion among the nucleus members of the Editors' Network. For the sake of simplicity some related items and confusing or redundant topics were subsequently removed from the final questionnaire. Eventually, a total of 48 different items were included in the survey. Questions were grouped into three main areas of interest: (1) authors; (2) reviewers; (3) editors. Furthermore, additional feedback about the interest generated by the ICMJE 'uniform' COI disclosure initiative was also explicitly requested. Spaces for free text comments were made available for each main area of interest.

In June 2010 the web-based survey was sent from the ESC European Heart House to all editors-in-chief of the ESC NSCJ and, in a second wave (July 2010), to the ESC Affiliated Cardiac Societies. A specific claim was made for the editor-in-chief in person to complete the survey. The invitation suggested that a meeting between the editor-inchief, associated editors and corresponding journal staff should be organised, to discuss the results of the requested information, before returning the questionnaire. A URL link to the web-based survey was provided in the invitation letter to allow editors to enter the survey. When no answer was obtained the corresponding National Cardiac Society was contacted directly. Conventional mailing was also used as required. Up to five separate requests were sent over the 
year and thereafter missing journals were classified as nonresponders.

The final electronic records were carefully analysed by ESC personnel at the European Heart House and by the nucleus members of the ESC Editors' Network. Attention was paid to detecting missing data, major inconsistencies or errors. Additional clarifications were requested from the corresponding editors as needed. Data are presented as global results and anonymised for individual journals.

\section{Conflict of interest survey results}

A total of 46 journals answered the survey. Of these, 35 belong to the ESC NSCJ and 11 to journals of Affiliated Cardiac Societies. This represents a response of $83 \%(35 /$ 42) of known NSCJ and $58 \%$ (11/19) for Affiliated Cardiac Societies. ESC NSCJ are highly heterogeneous in objectives, format and in scientific content [13]. Accordingly, some editors declined to answer the survey because they felt that COI policies did not apply to their journals (lack of original articles, small bulletins, contents with just social news, etc.) (data not shown).

Table 1 summarises the main data regarding authors' COI. Nearly half of the journals had a specific policy on author COI. In most cases, emphasis was only on financial COI and on COI directly related to the submitted work. Few journals provided definitions or examples of COI. In nearly all cases where COI were requested this policy affected all kinds of submitted articles. Written attestation by the authors was widely requested. However, procedures to verify the accuracy of authors' COI disclosure were rarely implemented, although, under special circumstances, most editors eventually contact authors to clarify COI-related issues. Policies to deal with authors who fail to disclose COI were seldom in place. In most journals the editors decided when authors' COI should be published but, in some

Table 1 Journals policies on authors' conflicts of interest

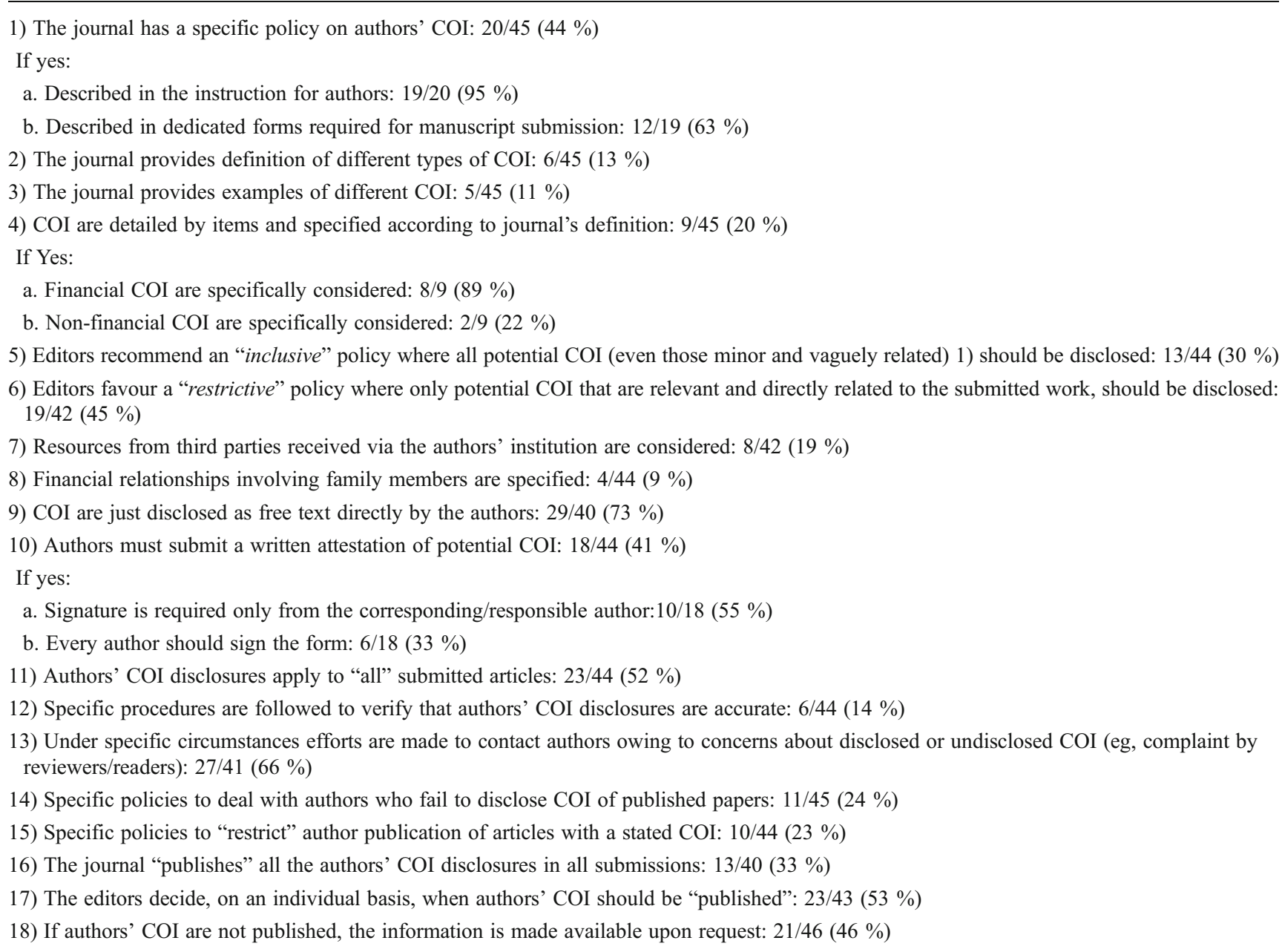

Data from the 46 journals answering the questionnaire (number of journals answering each question is presented). Not all journals responded to all questions. COI conflicts of interest 
Table 2 Journals policies on peer-reviewers' conflicts of interest

1) The journal has a specific policy on reviewers' COI: 11/43 (25\%)

2) Reviewers are required to explicitly state whether they have potential COI: 10/43 (23\%)

3) Reviewers must submit a written attestation of potential COI: 7/43 (16\%)

4) Frequency of request to disclose potential COI: only first invitation: $7 / 46$ (15\%); always: 10/46 (22\%); yearly: $5 / 46$ (11 \%)

5) Specific procedures are followed to verify that peer-reviewers' COI disclosures are accurate: $5 / 44(11 \%)$

6) It is suggested to reviewers that they "decline" the invitation if potential COI exists: 21/39 (54 \%)

7) There is a policy for "recusal" of reviewers with a declared COI: 6/42 (14\%)

8) Peer-reviewers' COI are always published: $1 / 44$ (2\%)

9) Editors decide, on an individual basis, when reviewers' COI should be published: 20/44 (45 \%)

10) If reviewers' COI are not published, the information is made available upon request: $15 / 46$ (33\%)

COI conflicts of interest

journals, this information was systematically published (Table 1).

Table 2 discloses data related to reviewers' COI. Only one-quarter of the journals had policies for reviewers' COI. In more than half of the journals reviewers were asked to decline the invitation to review if potential COI existed. However, recusal of reviewers due to potential COI was rare.

Table 3 displays the status of editors' COI among the corresponding journals. In most cases, policies in this regard were not implemented. Furthermore, very few journals had policies for delegating decisions to other editors or to invited guest editors. Only one-third of the editors were familiar with the new 'Uniform Disclosure Form' ICMJE initiative when they received the survey invitation. However, $90 \%$ of the editors considered the ICMJE COI proposal of potential value to their particular journals and most of them declared that they were willing to implement it within a relatively short period of time (Table 4).

\section{Discussion}

Industry-sponsored studies: friend or foe?

Research is becoming progressively complex and quality standards increasingly demanding [17-24]. As a result, conducting clinical studies is becoming more expensive and the role of sponsors to ensure the viability of research projects is becoming critical. However, funding from different sources may directly affect investigators and COI may inappropriately influence their actions or judgement [17-24]. Subtle biases in design and interpretation may arise when a sponsor stands to gain from the report [17].

Pharmaceutical and technological companies are responsible for most important advancements in medical knowledge [17-24]. Patients, doctors and society as a whole benefit from this unique effort and should be grateful for the research commitment by the industry. More than $75 \%$ of all clinical trials are funded by drug companies [25, 26]. Likewise, the bulk of research has moved from academic centres to direct contracts between sponsors and private organisations $[27,28]$. For-profit, contract research organisations currently consume more than $60 \%$ of research funding from industry [25-28]. This could be a result of their ability to complete trials more rapidly than academic institutions $[8,25]$. This phenomenon explains the gradual loss of the academic establishment's influence on the 'research agenda' [25-29]. Although the most cited articles continue to be generated by authors with academic affiliations, the number of trials financed exclusively by industry has increased exponentially [30].

This paradigm shift has major consequences [25-29]. First, many scientifically relevant issues are decreasingly likely to be investigated (orphan studies). Second, many studies [8, 31, 32] suggest that, in comparison with non-sponsored research,
Table 3 Journals policies on editors' conflicts of interest

COI conflicts of interest
1) The journal has a specific policy on editors' COI: $8 / 45$ (18 \%)

2) Editors must submit a written attestation on potential COI: $6 / 8$

3) Frequency to disclose potential COI: only when appointed: 5/6; yearly: $1 / 6$

4) Specific procedures are followed to verify that editors' COI disclosures are accurate: $3 / 8$

5) There is a policy for "recusal" of editors with a declared COI: $3 / 8$

6) There is a policy for "delegating" handling decision to other (invited) editors: 4/7

7) Editors' COI are always published: $2 / 7$

8) If Editors' COI are not published, the information is made available upon request: $5 / 6$ 
Table 4 Feedback on the ICJME "uniform disclosure form" initiative
COI conflicts of interest; ICMJE international committee medical journals editors
1) Editor was familiar with the ICMJE initiative "before" receiving the survey: 15/42 (36 \%)

2) The initiative was considered of value to the "particular" journal: 38/42 (90\%)

3) Editors willing to implement the initiative within 3 years: 31/46 (67\%)

4) Main perceived advantages of the initiative (top 5):

a. Provides a common "uniform" platform for all journals: 42

b. All relevant information about $\mathrm{COI}$ is nicely presented and explained: 18

c. Allows easy update of the requested information: 12

d. Facilitates sequential submissions (if the paper is rejected by a journal): 11

e. Allows archiving of the requested information: 10

5) Main perceived disadvantages of the initiative (top 6):

a. Increases the complexity of the submission process: 29

b. Publishing in the journal all potential COI of every author is not feasible: 17

c. Verification of the disclosed/undisclosed COI remains impossible: 17

d. Increases editorial bureaucracy: 15

e. Too detailed and exhaustive: 14

f. The meaning of some potential COI (travel grants to meetings, etc.) might be perceived differently by American and European authors/journals/readers: 14 sponsored trials are published less frequently, raising the concern of publication bias [29]. Although the industry has been blamed for preferential publication of studies with positive outcomes, this problem also affects government-funded research [8, 31-35]. To reduce the effect of publication bias, trials must be registered in publicly accessible repositories [29]. Industry-supported research has also been associated with multiple reporting of studies with positive outcomes [8, 36]. This practice might affect results of subsequent reviews, metaanalyses and even clinical practice guidelines. Alternatively, industry sponsorship has been associated with publication delays or restrictions [8].

Finally, industry-sponsored trials have a three- to four-fold greater probability of obtaining favourable results than their nonsponsored counterparts [8, 31-33, 37, 38]. Interestingly, all these differences do not appear to be related to inferior methodology in industry-financed trials. Bekelman et al. [8] performed a systematic review of 1140 original studies demonstrating a statistically significant association between industry sponsorship and pro-industry conclusions. The study showed that financial relationships between industry, scientific investigators and academic institutions were widespread and that COI arising from these ties might significantly influence biomedical research. It was considered possible, however, that given limited resources, industry became selective enough to fund only potentially 'wining treatments' [8]. More recently, in a provocative study that included 324 cardiovascular trials published in the three medical journals with the highest impact factors, Ridker and Torres [39] analysed the probability of positive results according to the source of finance. Industry-financed trials more frequently obtained results favourable to drug or device than those financed by not-for-profit organisations. This was particularly evident in trials using surrogate endpoints [39].
Previous editorial surveys on conflicts of interests

In 1997, Krimsky and Rothenberg found that only $16 \%$ of journals across all scientific disciplines had COI policies [40]. In addition, existing editorial policies were often not readily available to submitting authors [41]. However, a substantial increase in the prevalence of COI disclosure occurred over time. Initially, most journals only required authors to disclose potential COI. Subsequently, journals encouraged authors to sign COI disclosure statements. If signed statements are not obtained from all authors, it remains possible that only the first author has reviewed the COI policy of the journal, leading to systematic under-reporting [6]. Interestingly, some journals that theoretically adhere to ICMJE recommendations do not have clear COI policies when critically analysed [6]. However, the journals with highest impact factors are more likely to have published COI policies [6, 41].

To better characterise COI policies, in 2006, Cooper et al. [7] performed a cross-sectional web-based survey of a convenience sample of 135 editors of peer-reviewed biomedical journals. The survey included questions about the existence of specific policies for authors, peer reviewers and editors, specific restrictions based on COI and the public availability of these disclosures. Ninety-three per cent of journals reported having an author COI policy but only $82 \%$ of these required a written attestation. While $77 \%$ reported collecting COI information on all author submissions, only $57 \%$ published all author disclosures. Eleven per cent of journals reported restricting author submissions based on COI. A minority of journals reported having a policy on reviewers' COI (46 \%) or editors' COI (40\%); among these, $25 \%$ and $31 \%$ of journals stated that they require recusal of peer-reviewers and editors if they report a COI. Only $3 \%$ of respondents published COI disclosures of peer reviewers and 
$12 \%$ published editors' COI disclosures, while $11 \%$ and $24 \%$, respectively, reported that this information was available upon request. In this survey, estimates were directly provided by the corresponding editors but no information was taken directly from the actual publications [7].

Other studies were more critical and analysed the information available directly from the journals yielding a different perspective. Interestingly, some of these studies focused on COI disclosures in cardiology. Weinfurt et al. [42] searched in PubMed for English-language articles published in 2006 that provided evidence or guidance about the use of coronary artery stents. As a premise, it was considered reasonable to expect that authors' COI were disclosed in similar ways in articles on the same topic published around the same time. A total of 746 articles with 2985 authors published in 135 journals, were analysed. Articles were examined to determine whether authors' financial interests were consistently reported. Eighty-three per cent of the articles did not contain disclosure statements for any author, $72 \%$ did not identify any funding source and only $6 \%$ of authors had an article with a disclosure statement. Additionally, author disclosure statements varied significantly from article to article. Notably, articles published in journals that endorsed the ICMJE guidelines were more likely to have disclosure statements for all authors. Similarly, articles in which all authors had disclosure statements were more likely to appear in journals with higher impact factors (median impact factor 11.6 vs 3.1). These investigators concluded that even rarely disclosed financial interests were not disclosed consistently, suggesting that there are problems with transparency in the cardiac literature with potential implications for patient care. Data suggested that the observed inconsistencies were a result of both journals' policies and authors' behaviour [42]. Many would argue that an inconsistent system of disclosure is more harmful than no disclosure at all.

More recently, Blum et al. [6] analysed COI policies of the top $10 \%$ of medical journals according to their impact factor. Instructions to authors and manuscript submission documents were electronically searched for phrases relating to COI using a standardised form. A total of 262 journals were analysed. Of these, $85 \%$ requested COI disclosure in the instruction to authors and an additional $4 \%$ in other submission documents. Links to specific policies on COI were found within the instruction for authors in only $25 \%$ of journals. Although $77 \%$ of journals provided definitions on COI, signed disclosure statements were required by only $54 \%$ of journals. Travel grant disclosure was requested by $12 \%$ of journals. Interestingly, journal category influenced COI disclosure requirements. This request was higher for internal medicine journals than for specialty journals, for journals in the top quartile according to impact factor and for journals endorsing the ICMJE guidelines [6].

Our data on ESC NSCJ COI policies and disclosure requirements suggest that this topic remains controversial and is not uniformly addressed by journals. We relied on self-reporting by journal editors. However, given the anonymous nature of our survey, we do not believe there is any reason to question the accuracy of their reports.

ICMJE uniform disclosure initiative

In October 2009 the ICMJE proposed an electronic 'uniform' format for COI disclosure [11]. Four main areas were addressed: authors' associations with entities that supported the submitted manuscript (indefinite time frame), associations with commercial entities with potential interest in the general area of the manuscript (time frame 36 months), financial association of their spouse and children and, finally, non-financial associations potentially relevant to the submitted manuscript. Each author should disclose resources received directly, or via the corresponding institution, which were used to complete the investigation. Additionally, all sources of revenues relevant to the submitted work paid by any third party before the submission and any relevant long-term relationship, even if ended, should be disclosed. Financial revenues should be disclosed regardless of the amount. A guide for authors and a completed sample was provided in PDF format. The reporting form was made available at www.icmje.org/coi_disclosure.pdf to be downloaded, completed and sent to the journal [11]. The form can be saved and used again - adding updated information - for a new manuscript. Each author should submit a separate form and is responsible for the accuracy and completeness of the submitted information [11].

The ICMJE allowed a period of beta-testing until April 2010 when submission of suggestions was encouraged [12]. As a result of the feedback comments, the form was modified. Concerns raised were mainly technical and ethical regarding inquiries about non-financial associations. Accordingly, clarity was enhanced for non-native English speakers (including a glossary of terms). Additionally, owing to the difficulties detected in defining non-financial COI, this section was also modified to be less intrusive (currently presented as an open query) while keeping its locus. Finally, queries about $\mathrm{COI}$ in family members were removed from the updated form [12].

The idea behind this initiative was to facilitate and standardise uniform disclosure of $\mathrm{COI}$ and to make the process easier for authors and less confusing to readers. This uniform 'universal' vehicle allows authors to save the electronic forms that can be updated as needed and eliminates the need for reformatting disclosure information for each new submission. Finally, this will eliminate apparent inconsistencies in the report of $\mathrm{COI}$ as a result of different journal policies [11, 12].

Additional editorial perspectives regarding conflicts of interests

Concerns about COI are not new. In his play Le Malade Imaginaire Molière satirised the relationship between the doctor and the druggist as they exploited the hypochondriac 
Argan for their own economic benefit [21]. Biomedical journals are particularly vulnerable to COI-related problems. As Richard Smith, the former editor-in-chief of the British Medical Journal, stated 'the quality of the journal will bless the quality of the drug' [43]. Therefore, it is easy to understand the extra scrutiny of industry-sponsored research by reviewers and editors [33]. Some editors require that authors of industry-associated research have their data analysis confirmed by a different source and others even ask for the raw data to be analysed by an independent academic statistician [20,33]. Some editors do not commission editorial or review articles from authors with potential COI as these may blur objectivity [19, 44, 45]. These pieces rely especially on interpretation and objectivity. However, assessing the importance of COI in opinion articles may be challenging. The dilemma is obvious: those authors with the greatest expertise are usually those with clearer potential COI [44]. Last, but not least, editors should also avoid the existence of marketing masquerading as education in their journals. Of note, industry support accounts for most of the funding of accredited continuing medical education (CME) programmes [19]. Some suggest that $\mathrm{CME}$ has become an insidious vehicle for the aggressive promotion of drugs and medical devices (even with off-label indications). Others consider CME a marketing machine and a lucrative process - with concealed payments to doctors - that undermines the independence of medical societies [19, 46].

Sometimes medical literature is produced in obscure ways. Professional writers, hired by the industry, may act as 'ghostwriters' to produce papers for which credibility will be subsequently increased by inviting academic physicians to act as a 'guest author' [33]. Unfortunately, these guest authors rarely make significant contributions to the design, analysis and data interpretation [33]. Conversely, many deserving industry scientists may be removed from the byline directly by the sponsors. Affiliation with a drug company should not be viewed as evidence of wrongdoing because, as previously emphasised, most important medical discoveries are generated by the pharmaceutical industry.

Journals typically use two main weapons to deal with COI: disclosure and exclusion [44]. However, as discussed, policies for COI vary widely among editors. Disclosure should not be considered as a panacea to deal with COI but, from an editorial perspective, casting daylight on the relationship between doctors and pharmaceutical companies represents the best way to untie this Gordian knot [44]. Editors should decide whether to publish the information disclosed by authors about potential COI. Editors have the 'discretion' to decide if the potential COI is important enough to be revealed [6]. However, it is unclear how editors decide whether to publish disclosures. Moreover, the extent to which such 'secret disclosure' may affect the integrity of the journal or the published work remains unknown [7]. Some journals systematically disclose all reported potential COI [6]. However, this strategy consumes major editorial resources and has been blamed for introducing prejudice in the judgement of manuscripts by readers and for tainting the full content of the article. The value of an exhaustive systematic disclosure of all potential COI remains highly controversial. This practice does not guarantee that the readers will be able to determine whether COI are meaningful or not. Indeed, this practice may be misleading because bias may be perceived when not present and overlooked when relevant. Although COI do not imply any improper behaviour, a McCarthyesque reaction to the term would wrongly support the presumption of guilty until proven innocent [23, 33, 47]. The pendulum is swinging towards increased oversight, but responsible editors should ensure that their readers enjoy the sweet spot in the middle, at least for the time being.

Editors are very busy and cannot conduct a forensic check on every submitted trial. Our survey is consistent with prior reports [7] suggesting that almost no journal has a formal policy of 'verification' of COI disclosures [7]. Editors are not policemen but, at the same time, it becomes clear that some action is expected when misconduct is detected. Many times editors behave as a 'toothless watchdog' regarding COI. Alternatively, other editors suggest that allegation of under-reported COI should be rigorously investigated [9]. However, editors do not have the resources required to conduct a full investigation to clarify elusive and multifaceted COI-related issues. In most cases their final role is just to raise the issue with the corresponding dean. Notably, formal 'corrections' about COI are rarely published.

All authors of this review support the importance of disclosing potential COI when a scientific paper is submitted for consideration to any ESC NSCJ. Moreover, when in doubt it is better to err on the side of over-disclosure and let the editors make the decision. The ICMJE Uniform Disclosure Initiative represents a milestone in this regard and paves the way for further transparency in biomedical publishing [11, 12]. Therefore, we encourage ESC NSCJ to progressively adapt their policies in order to be able to adhere to this editorial proposal. However, in this journey, some potential caveats should be carefully heeded. First, exhaustive disclosure of multiple, minor and vaguely related potential COI might 'dilute' the relevance of real major COI that most readers would be interested to know. Second, some relevant institutional COI are not openly disclosed to all corresponding researchers and, accordingly, these may be impossible to declare. Third, many major journals frequently allow senior international opinion leaders with clear (definitive and well-known) COI to systematically declare the absence of COI in their papers. Young scientists may 
perceive this as confusing and disturbing while others will regard this inconsistency as evidence that the whole process is completely hypocritical. Finally, major sociocultural differences among countries should be also taken into account. Most European doctors (including most editors in the byline of this article) frequently receive occasional travel grants from diverse pharmaceutical companies to attend medical society meetings and, up to now, these have not been systematically disclosed as potential COI. The situation, however, is quite different on the other side of the Atlantic where such practices have been considered inadequate or even misconduct for a number of years. In North America, direct support (including travel) of CME programmes by industry is prohibited while this practice is considered acceptable in most European countries [19]. NSCJ editors should be alerted to the need to deal with these vexing problems in their respective journals in line with local policies and practices [48]. Progressive steps should be taken to ensure a systematic approach to these COI-related editorial issues. However, commonsense and reason should prevail in order to achieve a balance between the pragmatic and utopian.

\section{Final remarks}

Consumers of medical scholarship expect a reliable system of disclosure, in which journals and authors make disclosures appropriately and consistently. There is a stigma surrounding the reporting of COI that should be progressively overcome. The ESC has recently defined a general policy for COI [49]. This review provides another framework to better understand COI from an editorial perspective. This survey on ESC NSCJ COI policies and disclosure requirements confirms that this topic is poorly — and not uniformly — dealt with by journals. Further actions are required to increase awareness of the importance of COI disclosure and to promote policies aimed at enhancing transparency in biomedical research.

Acknowledgments We are grateful for the support and assistance of Iris Chapuis, Lone Kristoffersen, Isabelle Collin and Muriel Mioulet from the ESC National Cardiac Societies Relations Department at the Heart House.

Disclosures None of the editors authors of this paper had any potential conflict of interest that needs to be disclosed in relation to this manuscript.

\section{References}

1. International Committee of Medical Journals Editors. Uniform Requirements for Manuscript Submitted to Biomedical Journals: Writing and Editing for Biomedical Publication. (Updated October 2008). Available: http://www.icmje.org/.
2. Council of Science Editors. CSE's White Paper on Promoting Integrity in Scientific Journal Publications. Editorial policy committee (2005-2006). Available: http://www.CouncilScienceEditors.org

3. World Association of Medical Editors. WAME recommendations on Publication Ethics and Policies for Medical Journals. Available: http://www.wame.org/resources/ethics-resources.

4. Committee On Publication Ethics. COPE. Code of Conduct and Best Practice Guidelines for Journal Editors. Available: http:// publicationethics.org/resources/guidelines.

5. Alfonso F, Bermejo J, Segovia J. New recommendations of the international committee of medical journal editors. Shifting focus: from uniformity in technical requirements to bioethical considerations. Rev Esp Cardiol. 2004;57(6):592-3.

6. Blum JA, Freeman K, Dart RC, et al. Requirements and definitions in conflict of interest policies of medical journals. JAMA. 2009;302(20):2230-4.

7. Cooper RJ, Gupta M, Wilkes MS, et al. Conflict of interest disclosure policies and practices in peer-reviewed biomedical journals. J Gen Intern Med. 2006;21(12):1248-52.

8. Bekelman JE, MPhil YL, Gross CP. Scope and impact of financial conflicts of interest in biomedical research: a systematic review. JAMA. 2003;289(4):454-65.

9. DeAngelis CD, Fontanarosa PB. Resolving unreported conflicts of interest. JAMA. 2009;302(2):198-9.

10. Studdert DM, Mello MM, Phil M, et al. Financial conflicts of interest in physicians' relationships with the pharmaceutical industry. Self-regulation in the shadow of federal prosecution. N Engl J Med. 2004;351:1891-900.

11. Drazen JM, Van der Weyden MB, Sahni P, et al. Uniform format for disclosure of competing interests in ICMJE journals. N Engl J Med. 2009;361(19):1896-7.

12. Drazen JM, de Leeuw PW, Laine C, et al. Toward more uniform conflict disclosures - The updated ICMJE conflict of interest reporting form. N Engl J Med. 2010;363(2):188-9.

13. Alfonso F, Ambrosio G, Pinto FJ, et al. European National Society cardiovascular journals. Background, rationale and mission statement of the "Editors' Club". Rev Esp Cardiol. 2008;61(6):64450 .

14. Alfonso F, Ambrosio G, Pinto FJ, et al. Editors' Network ESC Task Force. European Society of Cardiology national cardiovascular journals: the 'Editors' Network'. Eur Heart J. 2010;31(1):26-8.

15. Mills P, Timmis A, Huber K, et al. The role of European national journals in education. Heart. 2009;95(24):e3.

16. Alfonso F. The Editors' Network of the European Society of Cardiology. Eur Heart J. 2011;32(8):919-21.

17. Schwartz RS, Curfman GD, Morrissey S, et al. Full disclosure and the funding of biomedical research. N Engl J Med. 2008;358 (17):1850-1.

18. Simone J. More interest in conflicts of interest. Lancet Oncol. 2009; 10:836-7.

19. Conti RC. Conflict of interest. Clin Cardiol. 2009;32:666-7.

20. Fontanarosa PB, Flanagin A, DeAngelis CD. Reporting conflicts of interest, financial aspects of research and role of sponsors in funded studies. JAMA. 2005;294(1):110-1.

21. Alpert JS. Doctors and the drug industry: how can we handle potential conflicts of interest? Am J Med. 2005;118(2):99-100.

22. Alpert JS. Doctors and the drug-industry: further thoughts for dealing with potential conflicts of interest? Am J Med. 2008;121 (4):253-5.

23. Lanier WL. Bidirectional conflicts of interest involving industry and medical journals: who will champion integrity? Mayo Clin Proc. 2009;84(9):771-5.

24. Bove A. Relations with industry: thoughts on claims of a broken system. J Am Coll Cardiol. 2009;54(2):177-9.

25. Bodenheimer $\mathrm{T}$. The uneasy alliance: clinical investigators and the pharmaceutical industry. N Engl J Med. 2000;342(20):1539-44. 
26. Goldacre B. Is the conflict of interest unacceptable when drug companies conduct trials on their own drugs? Yes. BMJ. 2009;339:b4949.

27. Davidoff F, de Angelis CD, Drazen JM, et al. International Committee of Medical Journal Editors. Sponsorship, authorship and accountability. Lancet. 2001;358:854-6.

28. Johns MM, Barners M, Florencio PS. Restoring balance to industry-academia relationships in an era of institutional financial conflicts of interest: promoting research while maintaining trust. JAMA. 2003;289(6):741-6.

29. Alfonso F, Segovia J, Heras M, et al. Publication of clinical trials in scientific journals: Editorial issues. Rev Esp Cardiol. 2006;59 (11):1206-14.

30. Patsopoulos NA, Analatos AA, Ioannidis JP. Origin and funding of the most frequently cited papers in medicine: database analysis. BMJ. 2006;332(7549):1061-4.

31. Lexchin J, Bero LA, Djulbegovic B, et al. Pharmaceutical industry sponsorship and research outcome and quality: systematic review. BMJ. 2003;326(7400):1167-70.

32. Finucane TE, Boult CE. Association of funding and findings of pharmaceutical research at a meeting of a medical professional society. Am J Med. 2004;117(11):842-5.

33. Hirsch LJ. Conflicts of interest, authorship, and disclosures in industry-related scientific publications: The tort bar and editorial oversight of medical journals. Mayo Clin Proc. 2009;84(9):811-21.

34. Krzyanowska MK, Pintilie M, Tannock IF. Factors associated with failure to publish large randomized trials presented at an oncology meeting. JAMA. 2003;290(4):495-501.

35. Chan AW, Krleza-Jerić K, Schmid I, et al. Outcome reporting bias in randomized trials funded by the Canadian Institutes of Health Research. CMAJ. 2004;171(7):735-40.

36. Alfonso F, Bermejo J, Segovia J. Duplicate or redundant publication: can we afford it? Rev Esp Cardiol. 2005;58(5):601-4

37. Hirsch L. Randomized clinical trials: what gets published, and when? CMAJ. 2004;170(4):481-3.
38. Kjaergard LL, Als-Nielsen B. Association between competing interests and authors' conclusions: epidemiological study of randomised clinical trials published in the BMJ. BMJ. 2002;325 (7358):249.

39. Ridker PM, Torres J. Reported outcomes in major cardiovascular clinical trials funded by for profit and not-for-profit organizations: 2000-2005. JAMA. 2006;295(19):2270-4.

40. Krimsky S, Rothenberg LS. Conflict of interest policies in science and medical journals: editors practices and authors disclosures. Sci Eng Ethics. 2001;7(2):205-18.

41. Ancker JS, Flanagin A. A comparison of conflict of interest policies at peer-reviewed journals in different scientific disciplines. Sci Eng Ethics. 2007;13(2):147-57.

42. Weinfurt KP, Seils DM, Tzeng JP, et al. Consistency of financial interest disclosures in the biomedical literature: The case of coronary stents. PLoS ONE. 2008;3(5):e2128.

43. Smith R. Medical journals are an extension of the marketing arm of pharmaceutical companies. PLoS Med. 2005;2(5):e138.

44. Editors T. Publishing commentary by authors with potential conflicts of interest: When, Why and How. Annals Intern Med. 2004;141 (1):73-4.

45. Vorobiof G. Do conflict of interest really matter or does no one read the fine print anyway? J Am Coll Cardiol. 2008;51(19):1911.

46. Tanne JH. US Senate committee investigates conflicts of interest in industry funded medical education. BMJ. 2009;339:b3139.

47. Rothman KJ. Conflict of interest. The new McCarthyism in science. JAMA. 1993;269(21):2782-4.

48. Avanzas P, Bayes-Genis A, Pérez de Isla L, et al. Ethical considerations in the publication of scientific articles. Rev Esp Cardiol. 2011;64(5):427-9.

49. Relations between professional medical associations and the health-care industry, concerning scientific communication and continuing medical education: a Policy Statement from the European Society of Cardiology Eur Heart J. 2012 March; 33(5): 666-674 